\title{
Field estimates of groundwater discharge - Great Artesian Basin, South Australia
}

\author{
$\underline{\text { J.F. Costelloe }}^{\mathrm{a}}$, V. Matic ${ }^{\mathrm{a}}$, A.W. Western ${ }^{\mathrm{a}}$, J.P. Walker ${ }^{\mathrm{b}}$, M. Tyler \\ ${ }^{a}$ Department of Infrastructure Engineering, University of Melbourne, Victoria, 3010 \\ ${ }^{b}$ Department of Civil Engineering, Monash University, Victoria, 3800 \\ ${ }^{c}$ Olympic Dam Operations, BHP Billiton, Roxby Downs, SA, 5725 \\ Email:.jcost@unimelb.edu.au
}

\begin{abstract}
Understanding the water balance of large groundwater systems is fundamental for the sustainable management of the resource. However, measuring many of the major components of the water balance pose considerable challenges and are thus estimated through modelling. A shortcoming of the modelling approach is that the water balance may have high bias and uncertainty due to insufficient information. The vertical leakage (i.e. discharge to upper aquifers or the unconfined water table) component of the Great Artesian Basin (GAB) is an example of a poorly constrained but large component of the water balance of Australia's largest groundwater resource. This paper reports on the use of field measurements and remote sensing to estimate the evaporative discharge along the southwestern margin of the GAB in South Australia, as this flux provides an upper bounds of vertical leakage along this part of the GAB margin. These discharge estimates are compared to published estimates of vertical leakage from modelled simulations by the Bureau of Rural Sciences (BRS) steady-state GABFLOW model.
\end{abstract}

Field estimates of evaporative discharge were made using eddy covariance station and micro-lysimeter measurements, and inversion of chloride/isotope soil profile measurments. The field estimates were assigned to three major land-types associated with areas of increasingly higher evaporative discharge and progressively decreasing depths to the water table. These land-types were mapped using remote sensing and digital elevation data, with characteristically higher soil moisture, salt precipitation and lower surface temperature compared to areas distal to discharge zones. Based on the field measurements, broad ranges of evaporative discharge $\left(0.5-10,10-100\right.$ and $\left.100-300 \mathrm{~mm} \mathrm{y}^{-1}\right)$ were assigned to the major land-types; landtypes were mapped using both quantitative classification of remote sensing imagery and semi-quantitative mapping of landforms using a variety of remotely sensed and field data. The remote sensing method provided a probable minimum estimate, due to the spatial resolution of the satellite data being unable to map areas with heterogeneous mixtures of discharge and non-discharge surface characteristics. In contrast, the digital elevation method provided a maximum area of higher evaporative discharge $\left(>10 \mathrm{~mm} \mathrm{y}^{-1}\right)$ due to its more interpretative nature that lumped areas together, and the fact that fine-scale microtopography and vegetation variations within the mapped areas are largely ignored. The evaporative discharge areas mapped by this project were separated into western and eastern sub-basins, reflecting groundwater inflow from the western margin and eastern margin of the GAB respectively, and a mixing zone that received inflow from both subbasins.

The higher evaporative discharge zones mapped by quantitative classification of satellite data are $8-28 \%$ of the total South Australian vertical leakage component modelled by BRS (Table 4). Areas of evaporative discharge fed only from groundwater flowing from the western sub-basin are $7-24 \%$, while areas from the mixing zone are $1-3 \%$, and areas from the eastern sub-basin account for $<1 \%$ of the modelled total vertical leakage for South Australia, respectively. In comparison, the higher evaporative discharge zones estimated by landform mapping are $73-251 \%$ of the total vertical leakage component modelled by BRS (Table 4), with the western sub-basin being $64-216 \%$, the mixing zone being $5-22 \%$ and the eastern sub-basin being $4-13 \%$ of the modelled total vertical leakage, respectively. The mapped distribution of the high discharge areas has important implications for modelling of the GAB. In the western sub-basin, most of the estimated recharge can be accounted for by evaporative discharge in the high discharge zones located around the Basin margins, implying that vertical leakage rates distal to the margins are very low, and/or the inflow to this part of the $\mathrm{GAB}$ is currently underestimated. In contrast, the results for the eastern sub-basin suggest that vertical leakage rates around the South Australian portion of the Basin margin are low and that more of the vertical leakage component in the eastern sub-basin is occurring distal to the Basin margins. Consequently, the pathways for vertical leakage in the east are likely to be more complex than for the western sub-basin.

Keywords: Evaporative discharge, Leakage, Water balance, Field measurements 


\section{INTRODUCTION}

Understanding the water balance of large groundwater systems is fundamental to sustainable management of the resource. However, measurement of many major components of the water balance pose considerable challenges and are thus estimated through modelling. A shortcoming of the modelling approach is that with insufficient information, the water balance may have high bias and uncertainty. This can lead to some of the major fluxes being significantly over- or underestimated. For instance, surface recharge may be overestimated if other sources of inflow (e.g. leakage from underlying basins) are not well constrained by observed data. Similarly, on the outflow side of the water balance ledger, vertical leakage (i.e. discharge to upper aquifers or the unconfined water table due to artesian piezometric heads) could be assigned most of the uncertainty from having inadequate information on all inflow and outflow processes. The collection of field data to measure a previously unconstrained, major component of the water balance allows greater confidence to be placed on modelling of the resource and its sustainable use (Tyler et al., 1997). An example of such an approach is to measure evaporative discharge from saline playas in closed basins to determine the major outflow flux from these systems (e.g. Allison and Barnes, 1985; Kampf et al., 2005). Whilst the uncertainty ranges around the measured fluxes are commonly large they provide an important independent test of both the magnitude and distribution of the fluxes.

The vertical leakage of the Great Artesian Basin (GAB) is an example of a poorly constrained but large component of the water balance of Australia's largest groundwater resource (Habermehl, 1980; Woods, 1990; Welsh, 2000). This paper reports on the use of field measurements and remote sensing to estimate part of the leakage component occurring in areas showing high rates of evaporative discharge along the southwestern margin of the GAB in South Australia. The evaporative discharge fluxes are sourced from the unconfined water table and this may also contain a component of local meteoric recharge. As a result, the evaporative flux measurements provide an upper bound to the possible vertical leakage from the GAB. These discharge estimates are compared to published estimates of vertical leakage from the Bureau of Rural Sciences (BRS) steady-state GABFLOW model.

\section{THE GREAT ARTESIAN BASIN}

The Great Artesian Basin is the largest groundwater resource in Australia and one of the largest artesian basins in the world (Habermehl, 1980). It underlies 22\% of the Australian continent (Figure 1) and is the only practical water resource available to mining and pastoral operations through much of the arid and semi-arid zone of central and eastern Australia. Most of the utilised water resource of the GAB occurs in the basal Lower Cretaceous and Jurassic aquifers (J-K aquifers). These aquifers are typically hydraulically connected and considered as a single aquifer (Habermehl, 1980). It is evaporative discharge at least partially sourced by leakage from the J-K aquifers around the southwestern margin of the GAB that is the focus of this study.

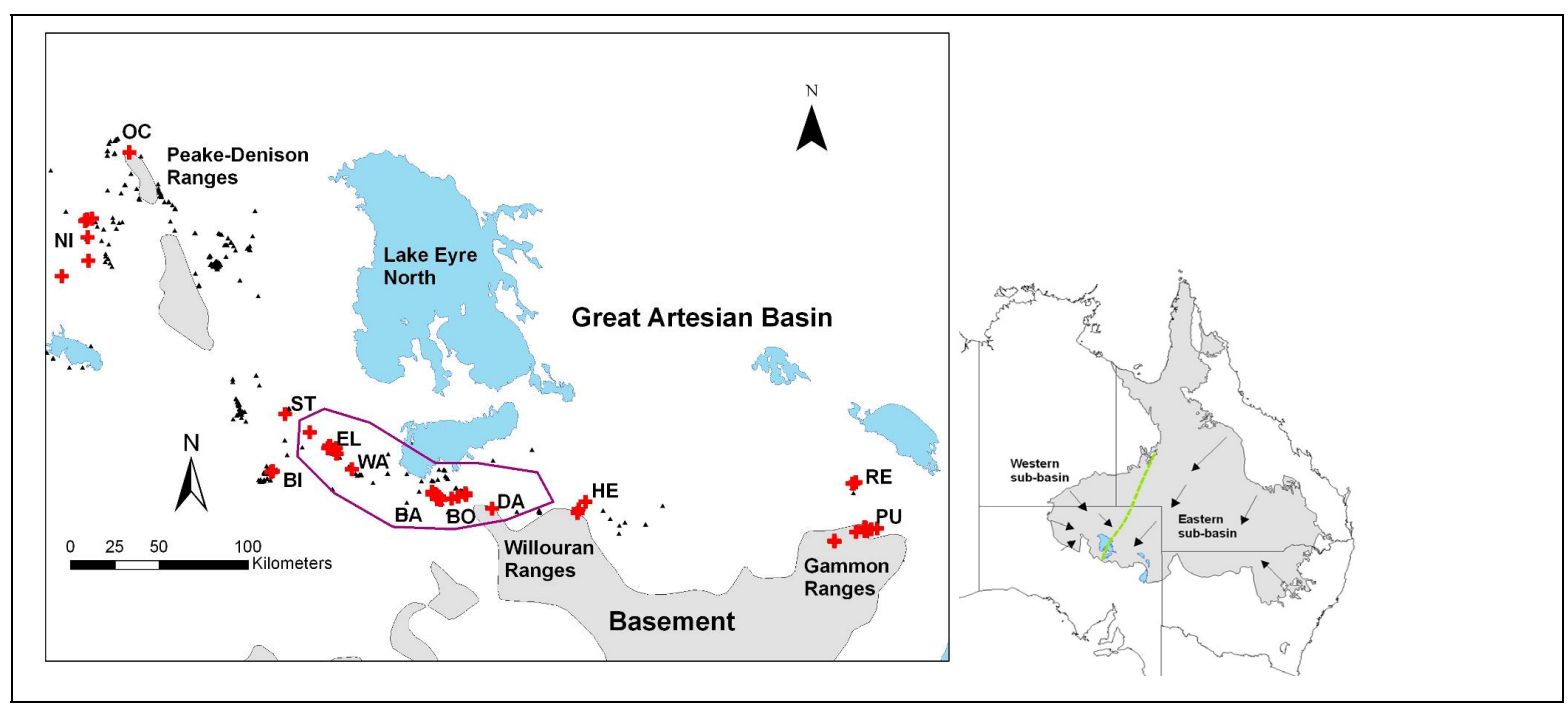

Figure 1. Location diagram of field areas within the GAB. Outcrop of Proterozoic basement forming the GAB margin is shown by grey polygons. Salt lakes are shown in blue. The discharge areas along the southwestern margin of the GAB are approximately shown by the position of artesian springs (black triangles). The locations of boreholes drilled for this study are shown as red crosses and the field area mentioned in the text is Public House Springs (PU). The mixing zone between the Eastern sub-basin and the Western subbasin is shown within the purple polygon. 
Within South Australia, the GAB can be divided into an eastern and western sub-basin (Figure 1). The much larger eastern sub-basin has groundwater flow from the east to the west, originating from recharge areas on the western slopes of the Great Dividing Range in Queensland and New South Wales. The smaller western sub-basin has its recharge areas along the western margin of the GAB in South Australia and Northern Territory with flow patterns from the west to the east. In the area around Lake Eyre, there is a mixing zone with contributions from the eastern and western sub-basins. Much of the groundwater flow throughout the GAB is focused towards discharge zones along the southwestern margin (Habermehl, 1980), with water discharged from the South Australian portion of the GAB by bores, natural springs ("mound springs") and vertical leakage. Due to the large spatial scale of the GAB, only modelling methods have been used to estimate the vertical leakage at a sub-basin scale (Welsh, 2000; 2006). Few field measurements are available to constrain the rate or regional distribution of this vertical leakage, despite it comprising such a large proportion of the GAB water balance in South Australia. Yet careful harvesting of the vertical leakage is considered to be the key to the sustainable use of the GAB resource in South Australia (AACWMB, 2004). Conceptually, some artesian water could be harvested that would otherwise be discharged by upwards leakage into the less important unconfined water table. The only study to have measured discharge rates in South Australia through the soil profile was by Woods (1990) near Lake Eyre South where rates of 3.0 - 7.0 $\mathrm{mm} \mathrm{y}^{-1}$ were estimated. Increased water resource demand, particularly from mining operations, requires improved understanding of natural discharge processes in the GAB. This will lead to improved protection of unique ecosystems (e.g. mound springs) dependent on flow from the GAB and greater security of supply for all users of the $\mathrm{GAB}$ resource

\section{METHODS}

\subsection{Field Measurements}

Field estimates of evaporative discharge were measured using point-based field techniques; eddy covariance stations, micro-lysimeters and chloride/isotope soil profile modelling. Data were collected along the southwestern margin of the GAB in northern South Australia during four field trips between 2007-2009.

Microlysimeters were installed in the high discharge zones evidenced by salt precipitation at surface and moist soils. The microlysimeters consisted of a $0.3 \mathrm{~m}$ length of $0.09 \mathrm{~m}$ diameter PVC pipe (or $0.1 \mathrm{~m}$ diameter steel pipe) hammered into the surface to obtain a soil core. The soil core was excavated and the bottom of the pipe capped, prior to installation into another PVC pipe of slightly larger diameter and inserted into the soil from where the previous pipe was removed. Both pipes were installed flush with the ground surface, taking care that disturbance of the salt/surface crust of the soil core and surrounding ground surface was minimized. The microlysimeters were then weighed daily at approximately the same time of day over a 4-7 day period. The daily weight loss was converted to a volumetric water loss and expressed as an evaporative loss in $\mathrm{mm}$ using the cross-sectional area of the microlysimeter.

An eddy covariance station was also installed in the high discharge zones together with the microlysimeters. The installation used a three-dimensional sonic anemometer (CSAT3, Campbell Scientific) and a gas analyser (LICOR 7500) to measure rates of actual evapotranspiration above the ground surface of the saline discharge zones. The atmospheric sensors were installed approximately $2.5 \mathrm{~m}$ above the ground surface and were operated at $10 \mathrm{~Hz}$ while averaging fluxes over 30 minute intervals. The $2.5 \mathrm{~m}$ height of the instrumentation gave an upwind fetch (or area providing the evapotranspiration flux) in the region of 250-300 $\mathrm{m}$. Radiation and soil heat flux measurements were also made to allow for calculation of energy balance closure.

Shallow cored auger holes ( $<6 \mathrm{~m}$ depth) were drilled within $1 \mathrm{~km}$ of the same high discharge areas, and the chloride concentration and oxygen isotope $\left(\delta^{18} \mathrm{O}\right)$ values of soil water samples used to estimate long term flux rates through the unsaturated sections of the soil profile, using a steady state advection-diffusion model (Barnes and Allison, 1983). In total, soil profile samples were obtained from 28 shallow boreholes in a variety of locations. Selected samples from each profile were analysed for chloride and $\delta^{18} \mathrm{O}$ concentration and gravimetric soil water content $(\theta)$. Typically, the first $0.5 \mathrm{~m}$ of the core profile from the surface was continuously sampled at $0.1 \mathrm{~m}$ intervals (usually $0.05 \mathrm{~m}$ interval for the surface sample). At greater depths, 1 2 samples of $0.1 \mathrm{~m}$ length were selected over each $0.5 \mathrm{~m}$ of cored soil profile.

The field estimates of diffuse discharge were assigned to three major land-types associated with areas of increasingly higher evaporative rates (see description below). These land-types were mapped using remote sensing, digital elevation data and field observations. 


\subsection{Remote Sensing}

A conceptual framework was used to classify areas of high evaporative discharge into relatively homogenous areas based on surface characteristics. Areas with shallow water tables (typically $<1 \mathrm{~m}$ deep) allow water to rise through capillary action to the near surface (i.e. within $0.05 \mathrm{~m}$ of the surface) and are classified as the Liquid Transport Zone (LTZ). These areas typically have the highest discharge rates and are characterized by moist soils, significant salt precipitation at the surface and relatively low surface temperatures. As the depth to the water table increases, the evaporation front occurs below the ground surface with water transport in both liquid and vapour phases in the near surface environment. Such areas are classified as the Mixed Transport Zone (MTZ). As a result, these discharge areas are characterized by drier soils, with less salt precipitation at surface and a lower temperature contrast with the surrounding dry ground. With increasing depth to groundwater (i.e. water table depths approximately $>3-4 \mathrm{~m}$ ) the evaporation front occurs $>0.1 \mathrm{~m}$ below the ground surface and vapour transport dominates at the surface (classified as the Vapour Transport Zone (VTZ)). These areas no longer have any observable salt precipitation; contain dry surface soils and no temperature contrast with the surrounding dry ground. Field mapping indicated that a fourth zone occasionally occurs around the GAB discharge areas (termed the carbonate zone), that comprised areas of flat-lying massive carbonate layers. These layers typically occur at a particular topographic level, can be 1- 2 $\mathrm{m}$ thick, and can extend under alluvial-colluvial cover away from the spring groups and high discharge zones and so their extent cannot be accurately measured with remote sensing.

Due to its suitable spatial and spectral resolution in mapping discharge scale processes, Landsat indices were used for classification. Landsat index (Band2-Band5)/(Band2+Band5), which highlights the short wave infrared soil moisture absorption feature, was used to delineate the LTZ. Landsat index (Band2xBand 3$)^{0.5}$ was used to map the MTZ by making use of the high albedo of salt crusts. The land-types were mapped using both quantitative (automated) classification of remote sensing data and semi-quantitative mapping of landforms using a variety of remotely sensed (including high spatial resolution aerial photography and Quickbird images) and field data. The former method provided a probable minimum estimate, due to the spatial resolution of the Landsat and ASTER satellite data $(30 \mathrm{~m}$ pixel size) being unable to distinguish between areas with heterogeneous mixtures of discharge and non-discharge surface characteristics. In contrast, the latter method provided a maximum area of higher evaporative discharge $\left(>10 \mathrm{~mm} \mathrm{y}^{-1}\right)$ due to its more interpretative nature that lumped areas together and largely ignored the fine-scale microtopography and vegetation variations within the mapped areas.

\section{RESULTS}

\subsection{Field Measurements of Discharge}

The field measurements of evaporative discharge for each of the three techniques were stratified according to the location of the measurement point within the conceptual discharge zones mapped using remote sensing (Table 1). All techniques showed wide ranges but a consistent decrease in discharge rates moving between zones and coinciding with an increase to the depth of the water table. Based on the field measurements, broad ranges of evaporative discharge were assigned to the major land-types (Table 1). No definitive measurements were available from the carbonate zone due to the difficulty in drilling soil profiles through the massive carbonate layer. However, the very low soil moisture in the near surface of the carbonate zone indicates that it would share a similar range in discharge as the VTZ but with a decreased upper limit.

Table 1. Range of field measured evaporative discharge for the different zones. The mean or median range (soil profile modeling only) for each method and zone are given in brackets.

\begin{tabular}{|l|c|c|c|c|}
\hline \multicolumn{1}{|c|}{ Zone } & Microlysimeters & Eddy covariance & Soil profile modelling & Final range \\
\hline & $\mathrm{mm} \mathrm{y}^{-1}$ & $\mathrm{~mm} \mathrm{y}^{-1}$ & $\mathrm{~mm} \mathrm{y}^{-1}$ & $\mathrm{~mm} \mathrm{y}^{-1}$ \\
\hline LTZ & $96-542(279)$ & $188-209(197)$ & $2-456(24-235)$ & $100-300$ \\
\hline MTZ & $41-240(105)$ & $56-110(82)$ & $0.4-86(1-47)$ & $10-100$ \\
\hline VTZ & - & - & $0-12(2-7)$ & $0.5-10$ \\
\hline Carbonate & - & - & - & $0.5-5$ \\
\hline
\end{tabular}

\subsection{Mapping of Discharge Areas}

The remote sensing techniques (automated classification and landform mapping) were only able to map the high discharge zones (LTZ , MTZ and carbonate) and could not constrain the peripheral 'halo' of the VTZ around these areas. As can be seen in Figure 2, the high discharge zones only form a very small part of the 
landscape. Comparing the automated classification mapping to the landform mapping suggests that the former is significantly underestimating the area of the high discharge zones while the latter is probably overestimating the area. Examination of the automated classification mapping results at the site scale (e.g. Public House springs site in Figure 2) confirms the underestimation by the automated classification mapping. In particular, areas with patchy salt precipitation but a heavy stone lag, which field mapping and water table depth would place in the MTZ, are not identified at the spatial scale of the Landsat and ASTER resolution. The more interpretative 'lumping' nature of the landform mapping captures the outer boundary of the high discharge zones but at the expense of ignoring smaller scale heterogeneity. The results of the two mapping techniques (Figure 2, Table 2) consistently show that the high discharge zones are most prevalent in the western sub-basin of the GAB. In constrast, the basin margins in the eastern sub-basin are characterized by a relative paucity of areas with high evaporative discharge characteristics.

Table 2. Results for mapping of high discharge areas (LTZ, MTZ and carbonate) by automated classification and landform mapping.

\begin{tabular}{|l|l|l|l|l|l|l|l|l|l|}
\hline & \multicolumn{2}{|l|}{ Western Area $\left(\mathrm{km}^{2}\right)$} & \multicolumn{2}{l|}{ Mixing Area $\left(\mathrm{km}^{2}\right)$} & \multicolumn{2}{l|}{ Eastern Area $\left(\mathrm{km}^{2}\right)$} & \multicolumn{2}{l|}{ Total Area $\left(\mathrm{km}^{2}\right)$} \\
\hline & Automated & Landform & Automated & Landform & Automated & Landform & Automated & Landform \\
\hline LTZ & 68.5 & 601.2 & 10.0 & 46.0 & - & 35.2 & 78.5 & 682.4 \\
\hline MTZ & 34.0 & 353.5 & 4.3 & 84.4 & 7.3 & 24.4 & 45.6 & 462.3 \\
\hline Carbonate & 20.8 & 11.3 & - & 7.6 & 0.5 & - & 21.3 & 18.9 \\
\hline & $\%$ & $\%$ & $\%$ & $\%$ & $\%$ & $\%$ & $\%$ & $\%$ \\
\hline LTZ & 87.3 & 88.1 & 12.7 & 6.8 & - & 5.2 & 100 & 100 \\
\hline MTZ & 74.6 & 76.5 & 9.4 & 18.3 & 16.0 & 5.3 & 100 & 100 \\
\hline Carbonate & 97.7 & 59.8 & - & 40.2 & 2.3 & - & 100 & 100 \\
\hline
\end{tabular}

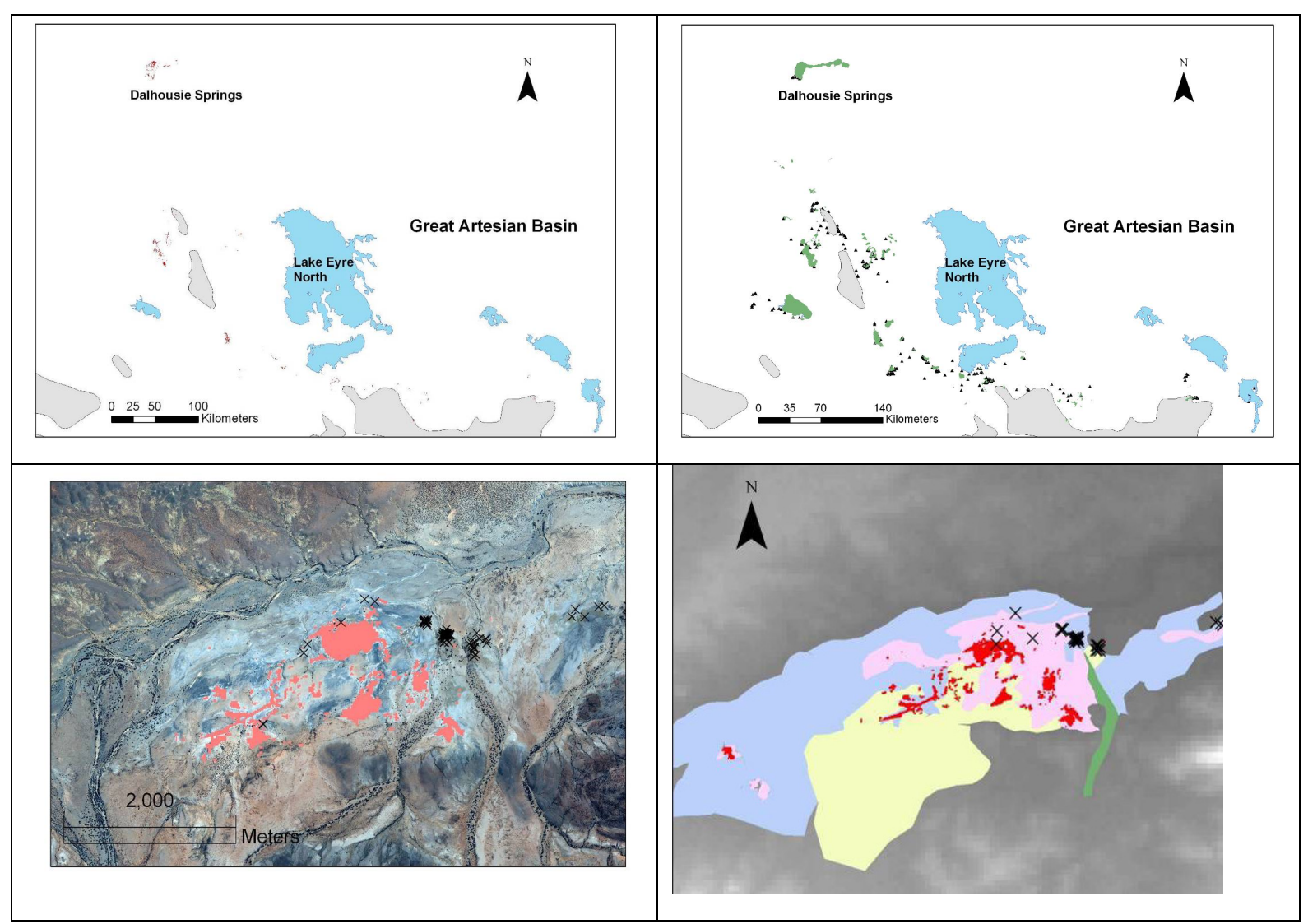

Figure 2. Mapping of discharge areas using remote sensing and landform mapping. Top left panel shows automated classification area of high discharge zones (LTZ and MTZ) as red polygons and in the top right panel the high discharge zones identified from landform mapping are shown as green polygons.. The bottom left panel shows a high spatial resolution Quickbird image at Public House Springs with high discharge areas mapped by automated classification as orange polygons. The bottom right panel shows the same location 
with high discharge areas mapped by automated classification as red polygons and by landform mapping as the pastel coloured polygons (pink-LTZ, blue-MTZ, yellow-carbonate).

\subsection{Flux Estimates}

The water balance for the GAB has previously been estimated by Habermehl (1980) and by steady-state and transient modelling at the whole-of-basin scale by the Bureau of Rural Sciences (Welsh, 2000; 2006). In this study we have used the 2003 Bureau of Rural Sciences (BRS) groundwater modelling estimate of vertical leakage in South Australia of $274 \mathrm{ML} \mathrm{d}^{-1}\left(100,010 \mathrm{ML} \mathrm{y}^{-1}\right)$, using the steady-state GABFLOW model (reported in Arid Areas Catchment Water Management Board, 2004). The water balance for the South Australian portion of the GAB from the BRS modelling is shown in Table 3.

The transient groundwater model developed for the GAB by the Bureau of Rural Sciences (Welsh, 2006) does not report on the South Australian water balance. This model reports that the net vertical leakage out of the model domain is only $87,688 \mathrm{ML} \mathrm{y}^{-1}$ for the whole GAB. However, Welsh (2006) identifies that this figure is likely to be underestimated because it is the residual figure after net leakage into and out of each model cell is cancelled. In addition, the vertical leakage flux was minimised during the model calibration. For these reasons the steady state modelled fluxes (Table 1) are used when comparing the modelled vertical leakage to the evaporative discharge fluxes measured and estimated by this project. The evaporative discharge areas mapped by this project were separated into western and eastern sub- basins, reflecting groundwater inflow from the western and eastern margins of the GAB respectively, and a mixing zone that received inflow from both sub-basins.

Table 3. Summary of model flows (indicative) for the whole of S.A (AACWMBoard, 2004).

\begin{tabular}{|l|c|c|}
\hline & $\begin{array}{c}\text { Inflow } \\
\left(\mathrm{ML} \mathrm{y}^{-1}\right)\end{array}$ & $\begin{array}{c}\text { Outflow } \\
\left(\mathrm{ML} \mathrm{y}^{-1}\right)\end{array}$ \\
\hline Horizontal flow & 58,400 & 1,095 \\
\hline Bores & - & 46,720 \\
\hline Springs & - & 24,090 \\
\hline Recharge (western sub-basin) & 59,495 & - \\
\hline Vertical leakage & 54,020 & 100,010 \\
\hline SUM & 171,915 & 171,915 \\
\hline
\end{tabular}

Table 4. Estimated evaporative discharge (i.e. vertical leakage) fluxes for the southwestern margin of the GAB using mapping of high discharge areas by automated classification and landform mapping. The percentages are of the estimated flux relative to the total modelled vertical leakage flux for South Australia.

\begin{tabular}{|c|c|c|c|c|c|c|c|c|}
\hline & \multicolumn{2}{|c|}{ Western Area $\left(\mathrm{ML} \mathrm{y}^{-1}\right)$} & \multicolumn{2}{|c|}{ Mixing Area $\left(\mathrm{ML} \mathrm{y}^{-1}\right)$} & \multicolumn{2}{|c|}{ Eastern Area $\left(\mathrm{ML} \mathrm{y}^{-1}\right)$} & \multicolumn{2}{|c|}{ Total Area $\left(\mathrm{ML} \mathrm{y}^{-1}\right)$} \\
\hline & Automated & Landform & Automated & Landform & Automated & Landform & Automated & Landform \\
\hline LTZ & $6851-20,553$ & $60,121-180,362$ & $1001-3004$ & $\begin{array}{l}4604- \\
13811\end{array}$ & 0 & $\begin{array}{l}3519- \\
10,556\end{array}$ & $\begin{array}{l}7852- \\
23556\end{array}$ & $\begin{array}{l}68,243- \\
204,730\end{array}$ \\
\hline MTZ & $340-3400$ & $3535-35,348$ & $43-433$ & $844-8441$ & $73-730$ & $244-2443$ & $456-4563$ & $\begin{array}{l}4623- \\
46,232\end{array}$ \\
\hline Carbonate & 4-104 & $2-57$ & 0 & $2-38$ & $0-2$ & 0 & $4-107$ & $4-95$ \\
\hline & $\%$ & $\%$ & $\%$ & $\%$ & $\%$ & $\%$ & $\%$ & $\%$ \\
\hline LTZ & $7-21$ & $60-180$ & $1-3$ & $5-14$ & 0 & $4-11$ & $8-24$ & $68-205$ \\
\hline MTZ & $0-3$ & $4-35$ & $<1$ & $1-8$ & $0-1$ & $0-2$ & $1-5$ & $5-46$ \\
\hline Carbonate & 0 & 0 & 0 & 0 & 0 & 0 & 0 & 0 \\
\hline
\end{tabular}

Ranges of evaporative discharge rates (Table 1) were estimated for LTZ, MTZ and carbonate discharge zones. These provide the upper and lower bounds for use in simple up-scaling discharge estimates using the automated and landform mapping of discharge areas. These were then applied to the areas of each discharge zone using both mapping approaches (Table 2) and the estimated fluxes of vertical leakage for the study area calculated as shown in Table 4. These discharge estimates are compared to total modelled estimates of GAB vertical leakage in South Australia (100,010 ML y ${ }^{-1}$ ) from the BRS steady-state GABFLOW model (Table $3)$. The discharge rates from the western sub-basin can also be compared to the modelled recharge within the western sub-basin $\left(59,495 \mathrm{ML} \mathrm{y}^{-1}\right)$. Note that the VTZ zone was not included in this analysis and nor were any GAB discharge zones around mound springs in the large salt lakes (e.g. Eyre South, Blanche, Callabonna, Frome). In the large salt lakes it is not possible to separate out areas of GAB vertical leakage from evaporation of unconfined groundwater sourced from surface inflow recharge. Therefore, the flux estimates do not represent the entire evaporative discharge component in South Australia but do indicate the main distribution of the areas of highest discharge. The higher (i.e. LTZ, MTZ, carbonate) evaporative 
discharge zones mapped by quantitative classification of satellite data are $8-28 \%$ of the total vertical leakage component within South Australia modelled by BRS (Table 4). Areas of evaporative discharge fed only from groundwater flowing from the western sub-basin are $7-24 \%$, areas from the mixing zone are $1-3 \%$ and areas from the eastern sub-basin account for $<1 \%$ of the modelled total vertical leakage for South Australia, respectively. The higher evaporative discharge zones estimated by landform mapping are $73-251 \%$ of the total vertical leakage component modelled by BRS (Table 4), with the western sub-basin being 64-216\%, the mixing zone being $5-22 \%$ and the eastern sub-basin being $4-13 \%$ of the modelled total vertical leakage, respectively.

\section{DISCUSSION AND CONCLUSIONS}

Despite the large uncertainties associated with the field estimates of discharge and the mapping of discharge areas, the results provide important constraints on the upward leakage loss term from the GAB. The measured discharges are larger than the range identified by Woods (1990) recognizing that those results were more focused on data collected in the MTZ and VTZ zones. The higher rates identified in this project for the LTZ and MTZ zones were consistent with results from salt lake environments (e.g. Allison and Barnes, 1985; Tyler et al., 1997). The mapped distribution of the high discharge areas has important implications for modelling of the GAB. In the western sub-basin, most of the estimated recharge can be accounted for by evaporative discharge in the high discharge zones located around the Basin margins, implying that vertical leakage rates distal to the margins are very low, and/or the inflow to this part of the GAB is currently underestimated. In contrast, the results for the eastern sub-basin suggest that vertical leakage rates around the Basin margin are low and that more of the vertical leakage component in the eastern sub-basin is occurring distal to the Basin margins. As a result, the pathways for vertical leakage are likely to be more complex than for the western sub-basin. For instance, overlying non-artesian aquifers could be capturing much of the vertical leakage from the artesian basal aquifers and control the spatial distribution of the ultimate destination of the leaked groundwater.

\section{ACKNOWLEDGMENTS}

Funding for this research was provided by Australian Research Council Linkage grant LP0774814, in conjunction with industry partners BHP-Billiton, Great Artesian Basin Coordinating Committee, Santos Limited and the South Australian Arid Lands Natural Resource Management Board.

\section{REFERENCES}

Allison, G.B., and C.J. Barnes (1985). Estimation of evaporation from the normally “dry” Lake Frome in South Australia. Journal of Hydrology, 78, 229-242.

Arid Areas Catchment Water Management Board. 2004. Water Allocation Plan: Far North Prescribed Wells Area. Arid Areas Catchment Water Management Board, Adelaide.

Barnes, C.J., and G. Allison (1983). The distribution of deuterium and ${ }^{18} \mathrm{O}$ in dry soils, 1. Theory. Journal of Hydrology, 60, 141-156.

Habermehl, M.A. (1980). The Great Artesian Basin. Australia. BMR Journal of Australian Geology and Geophysics, 5, 9-38.

Kampf, S.K., S.W. Tyler, C.A. Ortiz, J.F. Muñoz, and P.L. Adkins (2005). Evaporation and land surface energy budget at the Salar de Atacama, Northern Chile. Journal of Hydrology, 310, 236-252.

Tyler, S.W., S. Kranz, M.B. Parlange, J. Albertson, G.G. Katul, G.F. Cochran, B.A. Lyles, and G. Holder (1997). Estimation of groundwater evaporation and salt flux from Owens Lake, California, USA. Journal of Hydrology, 200, 110-135.

Welsh, W.D. (2000). GABFLOW: A steady state groundwater flow model of the Great Artesian Basin. Bureau of Rural Sciences, Canberra.

Welsh, W.D. (2006). Great Artesian Basin transient groundwater model. Bureau of Rural Sciences, Canberra.

Woods, P.H. (1990). Evaporative discharge of groundwater from the margin of the Great Artesian Basin, near Lake Eyre, South Australia. Ph.D. thesis, Flinders University, Australia. 